\title{
LAS FIESTAS DEL CINE: NOSTALGIA, EXCLUSIVIDAD Y OCASIÓN EN EL CINE-EVENTO EN ESPAÑA
}

Cinema festivals: nostalgia, exclusivity and occasion at event-led cinema in Spain

\author{
Rosana Vivar NAVAS ${ }^{\mathrm{a}}$ \\ Saint Louis University, Madrid \\ DOI: http://dx.doi.org/10.15366/secuencias2018.47.003
}

\begin{abstract}
RESUMEN
En los últimos años, junto a las películas de estreno que habitualmente se mantienen en cartel durante semanas, se han ido haciendo hueco toda una serie de proyecciones que ofrecen sesiones únicas fuera de la programación comercial. Estos pases, que se presentan en discontinuidad con la oferta de cine en salas, buscan mejorar y amplificar la experiencia del espectador poniendo énfasis en la fase más comunitaria y participativa de la asistencia al cine: sesiones dobles de cine de reestreno, sesiones de sing-a-long o de quote-a-long son algunas de las fórmulas que algunas salas están ensayando para atraer a más espectadores. El presente artículo se interesa por el fenómeno emergente del cineevento en España y analiza las formas en las que sus promotores están construyendo al público sobre una doble retórica: por un lado, discursos que remiten a un inconformismo profundo hacia las «pequeñas pantallas» y hacia la cultura masiva representada; y, por otro, discursos que conectan con gustos más mainstream y que identificamos con las propias cintas comerciales que estos eventos programan.
\end{abstract}

Palabras clave: cine-evento, experiencia cinematográfica, nostalgia, exclusividad, participación, cinefilia

\begin{abstract}
In the last few years, along with the standard features in cinemas, a series of screenings that offer unique sessions outside the commercial programme have carved themselves a niche in commercial theatres. These film screenings try to improve and to amplify the spectator experience by placing the emphasis on the community and participative dimensions of cinema-going. Double features and sing-a-longs or quote-a-longs are some of the formulas that some theatres are trying out in order to attract more spectators. This article examines the emergent phenomena of event-led cinema in Spain, and analyzes the double rhetoric with which its promoters are building the potential audience: on the one hand, discourses that refer to a profound discomfort towards online film consumption and towards mass culture. On the other hand, discourses that connect with rather mainstream tastes and that are identified by the commercial films that are part of these events programmes.
\end{abstract}

Keywords: event-led cinema, film experience, nostalgia, exclusivity, participation, cinephilia

[a] Rosana Vivar Navas es profesora adjunta en Saint Louis University, Madrid. Es Doctora en Comunicación Audiovisual por la Universidad de Granada con una tesis sobre festivales de cine y culturas lúdicas en España. Su línea de investigación se centra en el estudio de audiencias cinematográficas y festivales de cine, con un énfasis en las prácticas digitales y los usos que el público hace de los nuevos media en los eventos cinematográficos. Su trabajo se ha publicado en Participations, Journal of Audience and Reception Studies y Bloomsbury Academic. E-mail: rvivarnavas@gmail.com. 
Nos hemos habituado a escuchar en círculos académicos y profesionales que internet acabará con la experiencia tradicional de ir al cine. No podemos negar que el proceso de digitalización y la migración del cine a internet estén teniendo efectos colaterales que han trastornado de forma, quizás irreversible, la distribución de películas en salas comerciales grandes y -especialmentepequeñas en todo el mundo. El cierre de salas por toda España es hoy una realidad que llena las páginas de cultura de periódicos de tirada local y nacional y que confirman las estadísticas: en 2017, había ciento cuarenta y nueve locales de exhibición menos que en 2007, según datos de la Asociación para la Investigación de los Medios de Comunicación (AIMC) ${ }^{1}$. Sin embargo, en los últimos años esta tendencia muestra una doble cara. A la vez que se cierran tanto salas clásicas como multicines en ciudades de toda España, proliferan proyectos que apuestan por otras fórmulas de visionado en salas: el pase único, el cine de reestreno o las películas acompañadas de eventos. Proyecciones con música en vivo, encuentros con el director, servicio de bar, cine improvisado o pop-up ${ }^{2}$ o proyecciones en las que se fomentan formas catárticas de visionado, como el quote-a-long, el shout-a-long y el sing-a-long ${ }^{3}$, no solo han empezado a ser habituales en salas privadas, como los Cines Renoir en Madrid y Barcelona, Kinépolis o los Cines Príncipe en San Sebastián - por poner tan solo algunos ejemplos-, sino que están motivando la apertura de nuevos locales de exhibición gracias a iniciativas de aficionados y profesionales -como Artistic Metropol en Madrid o la sala Phenomena en Barcelona-. Desde las sesiones dobles de clásicos hasta los drive-ins y las proyecciones orquestadas en vivo, estas iniciativas buscan llevar más allá la experiencia «ordinaria» de ir al cine invitando al espectador a atravesar las barreras físicas de la sala y los protocolos que a menudo la acompañan.

El interés central de este artículo es explorar algunas de las manifestaciones del incipiente fenómeno del «cine evento» en España. Para ello, esta investigación recoge cuestiones relativas a las temáticas, aspectos técnicos y protocolos de visionado que rodean a estas sesiones, así como declaraciones de los organizadores de algunos de los eventos que más están despuntando en el panorama de sesiones cinematográficas festivas en nuestro país. A partir del análisis de los discursos que sus promotores usan para promocionar estas sesiones, se pretende demostrar que el auge de las proyecciones-evento en España es un fenómeno que debe entenderse en el marco de una modalidad de consumo en la que se pretende generar y potenciar relaciones de exclusividad entre el cine y los espectadores. En nuestro recorrido, veremos que estos discursos de exclusividad y distinción a menudo recurren a incitar una conciencia de minoría que bebe del desencanto por el actual panorama audiovisual y la dispersión del espectador en prácticas online.
[1] «Vigésimo Censo de Salas de Cine (mayo de 2017)», Asociación para la Investigación de los Medios de Comunicación. Disponible en: <http:// movierecord.com/new/archivos/CensoCines2017.pdf > (12/5/2018).

[2] El cine pop-up es la manera en la que comercialmente se llama a sesiones de reestreno en espacios emblemáticos, inusuales u ocultos de la ciudad que funcionan por un periodo limitado de tiempo.

[3] Mamma Mia (Phyllida LLoyd, 2008), Dirty Dancing (Emile Ardolino, 1987), Grease (Randal Kleiser, 1978) o Sonrisas y lágrimas (The Sound of Music, Robert Wise, 1965) son algunos de los filmes musicales que suelen motivar sesiones de sing-a-long, a menudo asociadas a un público mayoritariamente femenino (Richard McCulloch y Virginia Crisp. "Watch like a grown up... enjoy like a child': Exhibition, Authenticity, and Film Audiences at the Prince Charles Cinema». Participations. Journal of Audience and Reception Studies 13, n. ${ }^{\circ} 1$ [mayo de 2016]: pp. 188-217). En estas sesiones, que típicamente son amenizadas con dramatizaciones en directo, se invita al público a cantar durante la proyección y a asistir con disfraces que emulan la temática del filme. Por su parte, el quote-a-long está asociado a sesiones de culto -también conocidas como Midnight Movies- en las que el público, buen conocedor del filme, se hace eco de los diálogos citando en voz alta las frases más emblemáticas. El gran Lebowski (The Big Lebowski, Ethan Cohen y Joel Cohen, 1998), The Room (Tommy Wiseau, 2003) o The Rocky Horror Picture Show (Jim Sharman, 1975) son algunas de las películas más programadas en este tipo de sesiones. Final-

mente, el shout-a-long está asociado a proyecciones colectivas de culto, especialmente de cine de terror y fantástico, en las que las audiencias se involucran de forma irónica con el visionado del filme desarrollando un repertorio de frases, bromas y ocurrencias que gritan durante la película a modo de intervención cómica. En España, la Semana de Cine de Fantástico y de Terror de San Sebastián es bien conocida por sus rutinas de visionado festivas que bien podrían definirse como un shout-a-long. 
Para el estudio de la retórica de exclusividad sobre la que se vienen construyendo estas «sesiones-experiencia» se han tenido en cuenta declaraciones de los organizadores en ruedas de prensa, artículos y entrevistas publicados en periódicos nacionales y locales, información en las webs oficiales de los eventos y entrevistas personales mantenidas con algunos de los creadores de estas sesiones. En última instancia, el presente artículo ambiciona arrojar algo de luz sobre el consumo colectivo en torno al cine de culto en nuestro país, así como sobre otras experiencias catárticas que parecen estar escribiendo parte del futuro del visionado colectivo de cine.

\section{El auge del cine evento}

Aunque hace apenas cinco años se ha empezado a hablar de la emergencia del cine participativo, lo cierto es que las sesiones cinematográficas que incorporan la participación del público no son en absoluto un fenómeno nuevo. No tenemos más que remontarnos a experiencias tempranas de exhibición cinematográfica para comprender que la experiencia de recepción del espectáculo cinematográfico de los primeros años era bastante diferente a la que conocemos hoy. Vicente Benet describe el ambiente que reinaba en las proyecciones antes de que, ya entrado el siglo veinte, la cortina tapara la pantalla y el espectador se sumiera en la oscuridad. No solo los ruidos y las dificultades técnicas con las que lidiaba el proyeccionista dificultaban la sensación de inmersión que caracteriza al espectáculo cinematográfico en la actualidad, sino que el propio ambiente de la sala, más atento en ocasiones a lo que ocurría a su alrededor que a la propia película, disipaba toda atención de las imágenes ${ }^{4}$. De las crónicas de las que disponemos sobre las primeras proyecciones del cinematógrafo, en Madrid el 15 de mayo de 1896, sabemos que las sesiones apenas duraban quince minutos, que se exhibían películas de aspecto documental y que el público, además de mostrar su asombro ante las imágenes, se quejaba de la vibración luminosa de las proyecciones ${ }^{5}$. Asimismo, en uno de los pocos libros que habla de la recepción cultural del público en la era preclásica fuera de los Estados Unidos, Yuri Tsivian documenta algunas de las primeras memorias que se conservan de las primeras proyecciones en Odessa (Rusia), en las que se narra cómo los jóvenes y niños mascaban sonoramente y se tiraban comida unos a otros ${ }^{6}$.

[4] Vicente Benet, La cultura del cine (Barcelona, Paidós, 2004).

[5] Vicente Amorós, Luces de candilejas (Madrid, Espasa Calpe, 1991), pp. 189-90.

[6] Yuri Tsivian, Early Cinema in Russia and Its Cultural Reception (Londres; Nueva York, Routledge, 1998), p. 16.
Si estas prácticas han pasado prácticamente desapercibidas entre los historiadores del cine, solo recientemente la emergencia de sesiones festivas ha empezado a formar parte del estudio académico, concretamente en el Reino Unido, un país especialmente prolífico en lo que se refiere al estudio de las prácticas que rodean el consumo de cine. La irrupción, en 2007, en el panorama de distribución cinematográfica de la compañía Secret Cinema, especializada en la recreación de grandes proyecciones-espectáculo, y la inmediata proliferación de réplicas por todo Reino Unido (Sneaky Experience, Luna Cinema, Floating Cinema, Rooftop Film Club, Drive-in Film Club, Picnic Cinema o Hot 
Tub Cinema) pone de manifiesto la relevancia que este modelo industrial tiene en el panorama de la exhibición nacional. Uno de los objetivos del proyecto liderado por Helen Kennedy y Sarah Atkinson, en colaboración con Live Cinema UK y financiado por el Arts Council of England, ha sido precisamente el de definir y organizar de manera sistemática algunas de las cuestiones relativas a la economía, la distribución, la estética y la retórica de estos eventos, que ellas mismas sitúan como parte de toda una serie de cambios que se están produciendo en el marco de una economía creativa cada vez más participativa ${ }^{7}$. Con este propósito, se publica en 2017 Live Cinema. Cultures, Economies, Aesthetics, un volumen colectivo que asienta toda una terminología en torno al auge del llamado «cine en vivo» o «cine evento» y que documenta algunos de los casos en torno a este fenómeno en países como Reino Unido, Estados Unidos, Francia y España ${ }^{8}$. Helen Kennedy y Sarah Atkinson, editoras del volumen, definen este fenómeno como sigue:

[Se trata de] la tendencia creciente hacia la creación de un cine que escapa a las barreras del auditorio, donde las proyecciones son aumentadas de manera sincrónica con actuaciones en directo, localizaciones específicas, intervenciones tecnológicas, participación a través de redes sociales y todo tipo de momentos interactivos simultáneos que incluyen cantar, bailar, comer, beber e incluso oler - a todo esto, lo estamos definiendo como el campo de la cineexperiencia- ${ }^{9}$.

En el marco de la discusión terminológica que abre el volumen, mientras que el cine-experiencia hace referencia a proyecciones en las que la experiencia colectiva y, en general, silenciosa de ver una película en la sala se transforma en una suerte de fiesta multidisciplinar y participativa, el cine-evento abarca una definición más amplia que se refiere a la creación de eventos y espectáculos en directo en torno a la proyección de un filme ${ }^{10}$. Si bien en lo que sigue dedicaremos atención a algunas de las sesiones experiencia que acontecen en España, es el fenómeno más amplio del cine-evento al que dedicamos este artículo. De ahí que sea necesario diferenciar el fenómeno del cine-evento (event-led cinema) de las «proyecciones de eventos» (event cinema), un concepto que viene usándose tanto por la academia como en el contexto comercial para hacer referencia a las proyecciones en directo de grandes eventos culturales y deportivos (óperas, partidos de fútbol, obras de teatro, conciertos o danza), que están suponiendo una importante fuente de contenidos alternativos para salas comerciales equipadas para realizar sesiones de live-streaming ${ }^{11}$. La expansión de este modelo industrial basado en la proyección de eventos ha empezado a ser documentada por instituciones como el Arts Council del British Film Institute (BFI), que, en julio de 2016, publicaba un informe sobre el crecimiento económico que este sector está suponiendo en la emergente economía del cineevento en el país anglosajón ${ }^{12}$. Otro informe realizado por la Event Cinema Association (ECA) estimaba que las proyecciones de eventos facturarían en 2017 mil millones de dólares ${ }^{13}$.
[7] Sarah Atkinson y Helen Kennedy, «Inside-the-scenes: The Rise of Experiential Cinema» (Participations. Journal of Audience and Reception Studies, vol. 13, n. ${ }^{\circ}$, mayo de 2016), p. 139. Disponible en: <http:// www.participations.org/Volume\%2o 13/Issue\%201/S1/1. pdf $>(8 / 8 / 2017)$.

[8] Sarah Atkinson y Helen Kennedy (eds.), Live Cinema: Cultures, Economics, Aesthetics (Londres, Bloomsbury, 2017).

[9] Sarah Atkinson y Helen Kennedy, «Inside-the-scenes: The Rise of Experiential Cinema». (La traducción es nuestra).

[10] Sarah Atkinson y Helen Kennedy, «Inside-the-scenes: The Rise of Experiential Cinema», p.140.

[11] Martin Barker, Live to Your Local Cinema: The Remarkable Rise of Livecasting (Basingstoke, Palgrave Macmillan, 2013).

[12] Fiona Tuck y Mitra Abrahams, «Understanding the Impact of Event Cinema: an Evidence Review» (Trends Business Review for Arts Council and BFI, 2015). Disponible en <https://www.artscouncil. org.uk/sites/default/files/ download-file/Understanding_ the_impact_of_event_cinema. pdf $>(26 / 9 / 2018)$.

[13] «Rise of and Industry», (Event Cinema Association). Disponible en: <http://www. eventcinemaassociation.org/ annualreview/2013/Intro. html $>$ (7/10/2017). 
[14] «About» (Secret Cinema), $<$ https://www.secretcinema. org/about> (7/10/2017). (La traducción es nuestra).

[15] Helen Kennedy, «Funfear Attractions: the Playful Affects of Carefully Managed Terror in Inmersive 28 days later Live Experiences», en Sarah Atkinson y Helen Kennedy (eds.), Live Cinema: Cultures, Economics, Aesthetics (London, Bloomsbury, 2017).

[16] Benjamin Lee, «Does Star Wars Show Secret Cinema Has Lost the Force?» (The Guardian, 11 de marzo de 2015). Disponible en: <https://www. theguardian.com/film/film$\mathrm{blog} / 2015 / \mathrm{mar} / 11 / \mathrm{secret}$ cinema-star-wars-empirestrikes-back-lost-the-force> (1/4/2018).

[17] «About» (Secret Cinema), $<$ https://www.secretcinema. org/about> (7/10/2017). (La traducción es nuestra).
Como se ha mencionado más arriba, la compañía que más popularidad ha acumulado con sus proyecciones espectáculo ha sido Secret Cinema, un colectivo con base en Londres que recrea universos multidisciplinares y lúdicos en torno a la proyección de películas emblemáticas. Desde su inauguración en 2007 con la proyección del filme de Gus Van Sant, Paranoid Park (2007), Secret Cinema ha puesto en escena diferentes mundos fílmicos en pintorescas localizaciones de Londres, casi siempre escenarios industriales abandonados o recuperados, como antiguos almacenes en las afueras de la ciudad. Su estrategia consiste en combinar la proyección de clásicos y estrenos -El Club de los Poetas Muertos (Dead Poets Society, Peter Weir, 1989), Blade Runner (Ridley Scott, 1982), La Guerra de las Galaxias. El imperio contraataca (Star Wars. The Empire Strikes Back, Irvine Kershner, 1980), Paranoid Park, El Gran Hotel Budapest (The Grand Budapest Hotel, Wes Anderson, 2014) - con espectáculos en vivo que incluyen intervenciones tecnológicas, actuaciones teatrales, orquestaciones, sesiones con DJ e inmersivas recreaciones de los escenarios de los filmes con las que la compañía pretende crear «mundos participativos de 360 grados» ${ }^{14}$. Entre sus propuestas más ambiciosas, Secret Cinema puso en escena, entre abril y mayo de 2016, el filme de culto de temática zombi 28 días después (28 Days Later, Danny Boyle, 2002). Para la ocasión, la compañía organizó un espectáculo interactivo en el que recreó un mundo ficcional a semejanza del Londres postapocalíptico del film construyendo una gran base para infectados en una estación de metro al sur de Londres. Previo al evento, el público recibía en su cuenta de correo alertas ficticias del National Health Service (NHS) con información sobre la supuesta expansión de un virus rábico, así como reportajes de la BBC y pistas sobre el lugar donde se celebraría el evento. Llegado el gran día, el público era guiado hasta un gran campamento en el que se le ponía en cuarentena y se le invitaba a seguir un itinerario de juegos y escape-rooms que concluía con la proyección del filme en una sala multipantalla: una instalación para infectados en la que el público veía la película desde sus camas, rodeado de actores que interpretaban escenas de la película ${ }^{15}$.

Si bien es cierto que la principal limitación de acceso al evento la impone el precio prohibitivo de la entrada (setenta y cinco libras para el montaje de $E l$ imperio contraataca $)^{16}$, Secret Cinema se ha publicitado como un espectáculo accesible y atractivo a todo tipo de públicos poniendo en escena películas tan taquilleras como El imperio contraataca o Parque Jurásico (Jurassic Park, Steven Spielberg, 1993). No en vano, en su página web la organización lanza una propuesta que trata de acomodarse a una multiplicidad de miradas, prometiendo «desde proyecciones okupas (grassroots) en edificios abandonados de Londres hasta producciones a gran escala en algunos de los espacios más espectaculares en todo el mundo; creamos mundos participativos de 360 grados donde las fronteras entre el público y los actores, la realidad y el plató cambian constantemente» ${ }^{17}$. El uso de la palabra «grassroots», que aquí hemos traducido como proyecciones «okupas», tiene la intención de crear la impresión en el lector de que estas sesiones se celebran al margen de la cultura oficial y saltán- 
dose las licencias exigidas. Pese a que desde su primera sesión (Paranoid Park), en una sala improvisada bajo el Puente de Londres, Secret Cinema estableció su preferencia por los espacios remotos y pintorescos, la empresa siempre se ha movido dentro de la legalidad y en sintonía con el mercado de exhibición, distinguiéndose por el alto coste de sus entradas.

Esta ambición de ofrecerse simultáneamente como proyecciones autogestionadas, que brotan en algún rincón de la ciudad al margen de la

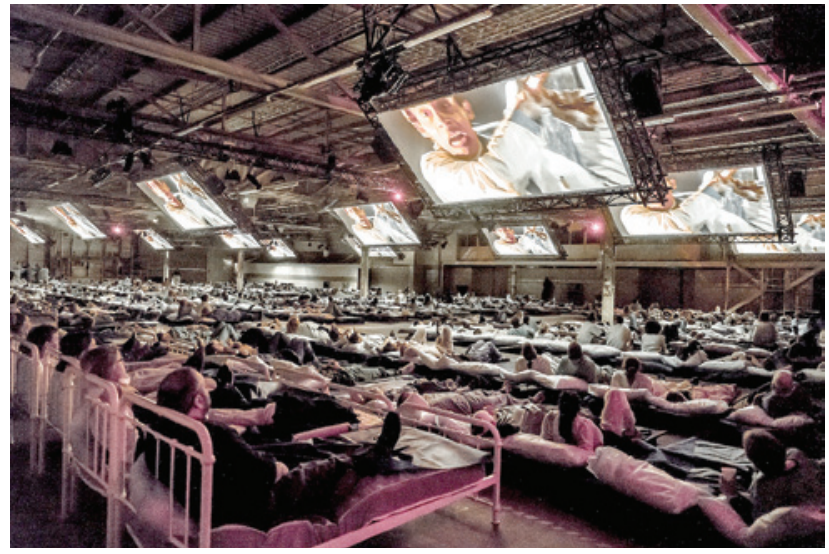

Secret Cinema. Momento de la proyección de 28 días después (28 Days Later, Danny Boyle 2002) en abril de 2016. cultura dominante, y como empresa productora de macro-eventos capaces de competir en la industria del espectáculo pone de manifiesto la vocación que este tipo de eventos tienen de presentarse como ocasiones que se sitúan en la frontera entre una cultura accesible y masiva, dedicada al común de los espectadores, y una cultura que se sostiene sobre discursos que construyen a la audiencia como parte de un sector cultural excluido del mainstream. Esto genera una ambigüedad de la que se hace eco la selección de películas que suelen formar parte de estas sesiones-experiencia.

Sin ánimo de sugerir que la emergencia de estas proyecciones son síntoma de un cambio en las preferencias de la audiencia, a continuación se proponen tres dimensiones sobre las que consideramos pivota la experiencia cultural de estas sesiones en España: (1) su presentación como «alternativa» al cine mainstream, (2) la recuperación nostálgica de la asistencia al cine frente al consumo doméstico online y (3) la construcción ritual de una sensibilidad cinéfila a través del evento. Con el fin de ubicar el presente artículo en continuidad con el trabajo realizado por otros autores dedicados al estudio del cineevento en diferentes partes del mundo, este estudio se nutre de publicaciones que, como las de Martin Barker ${ }^{18}$, Sarah Atkinson y Helen Kennedy ${ }^{19}$ o Richard McCulloch y Virginia Crisp ${ }^{20}$, se están encargando de dar cierta coherencia analítica a estas intervenciones.

\section{Sunset Cinema: el cine participativo como «alternativa»}

En España, el cine-evento ha adoptado diferentes modelos y versiones que en ningún caso alcanzan la espectacularidad ni el presupuesto de las sesiones de Secret Cinema. El colectivo Sunset Cinema, con base en Madrid, es probablemente la empresa que, con menos recursos y de manera simplificada, mejor ha trasladado el concepto del cine-experiencia y de las sesiones participativas al mercado español. Tras unos años formando parte del equipo de producción de

[18] Martin Barker, Live to Your Local Cinema: The Remarkable Rise of Livecasting.

[19] Sarah Atkinson y Helen Kennedy, «Inside-the-Scenes: The Rise of Experiential Cinema», pp. 139-151.

[2o] Richard McCulloch y Virginia Crisp, "Watch like a grown up ... enjoy like a child': Exhibition, Authenticity, and Film Audiences at the Prince Charles Cinema», pp. 188-217. 
[21] Jesús Mateos entrevistado por Ana González Rueda, «Cibeles como una propuesta distinta de cine de verano» (El Mundo, 9 de julio, 2015). Disponible en: <http://www.elmundo.es/madrid/2015/07/08 /559d4b60268e3ee0428b4591. html > (09/08/2017).

[22] La noche de Halloween y otros filmes de terror como $\mathrm{Ca}$ rrie (Brian de Palma, 1976) y La semilla del diablo (Rosemary's Baby, Roman Polanski, 1968) se proyectaron en otoño de 2016 en el ciclo Voodoo Cult Horror Movies Club, que Sunset Cinema celebró en los Cines Palafox hasta el traspaso de la sala a Yelmo en febrero de 2017.

[23] Ana González Rueda, «Cibeles como una propuesta distinta de cine de verano».

Secret Cinema en Londres, Jesús Mateos vuelve a España para empezar a programar sesiones de cine pop-up en espacios tan emblemáticos como el Palacio de Cibeles en Madrid (Cibeles de Cine), los Cines Palafox (Voodoo Cult Horror Movies Club), la terraza del hotel NH Collection Madrid Suecia o el puerto náutico de Alicante, donde la empresa arma un «cine flotante» en verano de 2017. Sunset Cinema arranca en 2014 con The Cinema (Cibeles de Cine a partir de 2015), una sala improvisada en la Galería de Cristal del Palacio Cibeles de Madrid que, de acuerdo con Mateos, ambiciona convertirse en «una alternativa a los cines de verano ${ }^{21}$.

Como parte del proyecto, cada verano, desde 2014, el Palacio de Cristal se convierte en anfitrión de ciclos temáticos acompañados de servicio de bar y menús especiales (como el menú temático creado para la proyección de $E l$ apartamento de Billy Wilder [The Apartment, 1960]), música en directo, photocall para el público, sesiones de maquillaje, exposiciones, karaoke, instalaciones de videomapping (como el realizado durante un homenaje a David Bowie en septiembre de 2016) o incluso clases de swing. Si atendemos a los títulos que Sunset Cinema ha recogido en los últimos tres años, resulta llamativo lo ecléctico de su selección, que abarca clásicos de la época dorada de Hollywood, blockbusters para toda la familia y películas que caen bajo la categoría del cine de culto, con títulos tan variopintos como La Princesa Prometida (The Princess Bride, Rob Reiner, 1987), Dentro del laberinto (Labyrinth, Jim Henson, 1986), Historias de Filadelfia (The Philadelphia Story, George Cukor, 1940), Akira (Katsuhiro Otomo, 1988), Persépolis (Marjane Satrapi y Vincent Paronnaud, 2007), Bella de día (Belle de Jour, Luis Buñuel 1967), Los amos de la noche (The Warriors, Walter Hill, 1967), Clerks (Kevin Smith,1994) o La noche de Halloween (Halloween, John Carpenter, 1978) ${ }^{22}$.

Pese a que tanto la variedad de títulos como lo emblemático de sus localizaciones apuntan a un intento de atraer a todo tipo de espectadores a las sesiones de Sunset, la empresa ha insistido en proyectar una imagen de exclusivi-

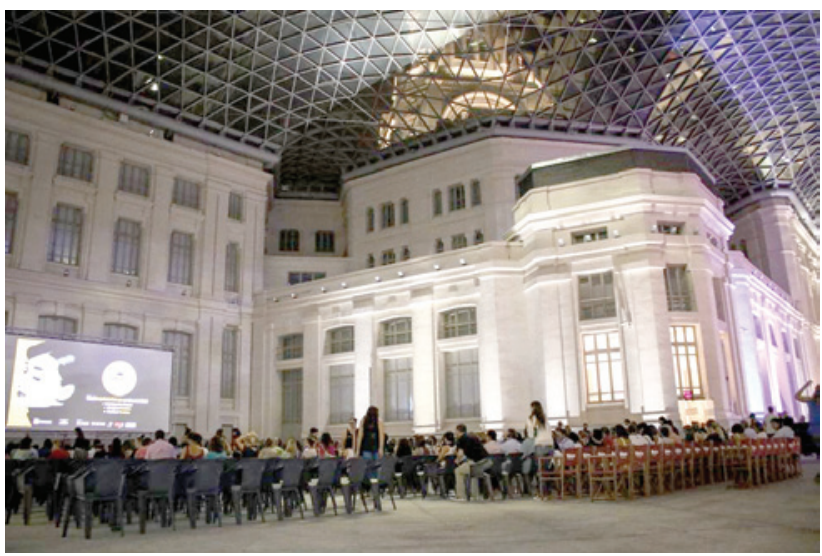

Galería de Cristal del Palacio de Cibeles en Madrid, espacio de proyección de Cibeles de Cine. dad poniendo el énfasis en la singularidad de sus proyecciones en contraste con la sesión de cine «ordinaria», una experiencia que el propio Jesús Mateos ha tachado de ser poco apetecible para el público actual. Con motivo de la inauguración de la temporada 2015 de Cibeles de Cine, Mateos justificaba la viabilidad de sus sesiones-evento argumentando que «al público le gusta ir al cine, pero quizá lo de meterse en una sala oscura durante dos horas ya no apetezca tanto» ${ }^{23}$. En una entrevista a Sight and Sound en 2010, el 
fundador de Secret Cinema, Fabien Riggall, contextualizaba la emergencia del cine evento en términos muy similares:

Cuanto más desconectados [físicamente] estamos con internet y las redes sociales, más queremos compartir experiencias. El multiplex no ha muerto, es un gran modelo de negocio; sin embargo, algunas personas buscan una experiencia cinematográfica diferente. Quieren que les reten, les inspiren; quieren una razón para conectar ${ }^{24}$.

Las palabras de Riggall y Mateos no solo nos ofrecen pistas sobre las máximas que perfilan el discurso oficial en torno al cine-evento, sino que presentan una serie de presunciones en torno a la experiencia del consumidor de cine que, en nuestra opinión, resultan problemáticas. En primer lugar, Riggall plantea que el cine-evento y, en extensión, el proyecto Secret Cinema surgen como una experiencia necesaria que pretende paliar una grave situación de pérdida en el marco de la vivencia del espectador. Su referencia a la creciente desconexión física del público no solo apunta a la idea de que internet y el uso de las tecnologías en el hogar están acabando con los lazos que garantizan la salud de la vida colectiva, sino que confirma la extendida creencia de que la especificidad del cine habita exclusivamente en el espacio (compartido y comunitario) de la sala. Este espacio representa para ambos organizadores un modelo que ha dejado de ser cauce de satisfacción para las nuevas audiencias. Tanto Riggall como Mateos concluyen que ver cine en la oscuridad no solo es algo de lo que el público se ha cansado, sino que se ha convertido en una forma obsoleta de ver películas. Es decir, deducen que las audiencias que se involucran en formas más festivas de visionado lo hacen porque han perdido el interés por el cine en la sala oscura, pero también por otras formas de visionado en las que se encuentran implicadas las nuevas tecnologías de la comunicación.

Estas afirmaciones, sin embargo, contrastan con averiguaciones recientes sobre la valoración que diferentes audiencias hacen de su experiencia en las salas y del placer que obtienen viendo una película en silencio. En un estudio etnográfico en torno a las audiencias de los cines Prince Charles de Londres, salas que se han especializado precisamente en el tipo de producto que ofrece Secret Cinema, Richard McCulloch y Virgina Crisp llaman la atención sobre el hecho de que un número sustancial de espectadores, a pesar de valorar el carácter único y participativo de estas sesiones, expresan su preferencia por un visionado más convencional e introspectivo, que ellos mismos percibían como una forma de ver películas más «apropiada» e, incluso, estéticamente superior a las vivencias que este tipo de eventos ofrecen ${ }^{25}$.

Otra de las afirmaciones que resultan problemáticas es la manera en la que el creador de Secret Cinema se refiere a las audiencias. Riggall no solo establece una relación jerárquica entre el cine-experiencia y las formas más «convencionales» de ver cine en salas (que él asocia con el múltiplex), sino que da por sentado que, en estas últimas, los espectadores asumen una posición pasiva. Además, al confirmar que «algunas personas» aventajadas buscan experien-
[24] Charles Gant, «Sharing the Secret», (Sight \& Sound 20, n. ${ }^{\circ} 9$, septiembre de 2010), p.9. (La traducción es nuestra).

[25] Richard McCulloch y Virginia Crisp, "Watch like a grown up ... enjoy like a child': Exhibition, Authenticity, and Film Audiences at the Prince Charles Cinema», p. 207. 
cias cinematográficas que «les inspiren», Riggall establece una distinción de estatus entre las audiencias consumidoras de experiencias cinematográficas anodinas, que se contentan con formas de recepción más convencionales, y las audiencias de Secret Cinema, capaces de confrontar experiencias cinematográficas nuevas que las estimulen intelectualmente. Aunque Mateos y Riggall promocionan formas de visionado que parecen distanciarse de la rectitud típica de los contextos cinéfilos, al posicionar sus eventos como lugares pensados para un público diferente, arriesgado y más preparado, están recurriendo a toda una serie de postulados que son propios de una caracterización conservadora de la cinefilia. Es decir, ambos, sostienen su discurso sobre una confrontación entre las audiencias más preparadas/activas y las menos preparadas/pasivas. Esta dicotomía reaparece en la presentación que Jesús Mateos hizo de la nueva temporada de Cibeles de Cine en 2015:

Nuestro público por lo general es joven, entre los 25 y los 45 años, moderno, cosmopolita...» y de ahí que [los organizadores de Cibeles de Cine] se permitan la licencia de ofrecer títulos más de autor, como la española Magical Girl, que «no es la típica película que esperarías en un cine de verano; nosotros tenemos propuestas que son bastante arriesgadas ${ }^{26}$.

En este extracto, observamos que Cibeles de Cine construye a su espectador a partir de una doble oposición: la que existe entre formas de recepción pasivas y activas, por un lado, y la que existe entre los textos culturalmente válidos y de autor y los títulos comerciales, por otro. Por un lado, al establecer que Magical Girl (Carlos Vermut, 2014) es una película «arriesgada» y, por tanto, portadora de los valores trascendentes propios de la alta cultura (no olvidemos que el filme ganó la Concha de Oro en el Festival de Cine de San Sebastián en 2014), Mateos está asociando ciertas películas a formas más complacientes de recepción y, como consecuencia, a unos espectadores que ven el tipo de películas que se proyectan en los cines de verano convencionales. No obstante, habría que hilar muy fino y reflexionar acerca de las connotaciones culturales y cinéfilas asociadas a Magical Girl, un filme que habiendo ganado la Concha de Oro el año anterior, se sitúa en su narrativa, su estilo y su elección de referencias culturales claramente del lado de la cultura popular, el cómic y la animación. Pero, además, la idea de ofrecer propuestas más arriesgadas conectaría con el producto participativo y multidisciplinar en el que se ha especializado la compañía Sunset Cinema. La posibilidad de encajar todas estas propuestas bajo el modelo tradicional y popular del «cine de verano» no deja de enfatizar el hecho de que Cibeles de Cine quiera promocionarse dentro del universo de referencias de la mayoría de los espectadores. En definitiva, las declaraciones de Mateos y de Riggall visibilizan el territorio fronterizo y ambiguo en el que se posicionan este tipo de eventos, un territorio al que se adscriben muchas de las propuestas cinematográficas que emergen hoy en el espacio público y que, como argumentaremos más adelante, se construyen

[26] Ana González Rueda, «Cibeles como una propuesta distinta de cine de verano». sobre la promesa de ofrecer al público una relación en exclusiva con los filmes y con el resto de espectadores. 


\section{Phenomena: el cine como acontecimiento}

Si Sunset Cinema se ha especializado en producir eventos cinematográficos que apuestan por una recreación espectacular y festiva del espacio cinematográfico, Phenomena pone un énfasis diferente en la vivencia del cine como evento/ acontecimiento. Además de devolverle a la proyección el ímpetu de las ocasiones únicas, lo atípico de las sesiones Phenomena es que el producto recibe un tratamiento especial. Después de seis años organizando sesiones itinerantes en diferentes cines en Barcelona, Madrid, Zaragoza y San Sebastián, así como en festivales, el proyecto Phenomena Experience se instala en 2014 en los antiguos cines Nápoles de Barcelona donde su creador, el cineasta Nacho Cerdà, recrea una suerte de templo cinéfilo que pretende ser un homenaje al ritual de ir al cine desde la llegada al vestíbulo, que emula los halls enmoquetados de los movie theaters norteamericanos (con evidentes referencias al hotel de El Resplandor [The Shining, Stanley Kubrick, 1980]), hasta la propia sala, donde un pesado telón de terciopelo rojo oculta una pantalla panorámica con proyector $4 \mathrm{~K}$ de $35 / 70 \mathrm{~mm}$. Desde su inauguración, Phenomena ha programado tanto cine de estreno como un variado repertorio de películas que combina ciclos dedicados a directores (como los dedicados a Brian de Palma, William Friedkin o Paul Thomas Anderson), sesiones Grindhouse, sesiones infantiles, masterclasses, maratones cinematográficos y programas dobles con los que Cerdà pretende «recuperar la magia de ir al cine» ${ }^{27}$.

Además de rescatar títulos que son familiares a los públicos de la generación de Cerdà, como Los Goonies (The Goonies, Richard Donner, 1985), Regreso al futuro (Back to the Future, Robert Zemeckis, 1985), La Junga de Cristal (Die Hard, John McTiernan, 1988) o Tiburón (Jaws, Steven Spielberg, 1975), Phenomena se presenta como una sala dedicada a mejorar la experiencia inmersiva del espectador usando las últimas tecnologías en imagen y sonido y recuperando las proyecciones en gran formato. No en vano, la sala se presenta en su página web como «un cine como los de antes y dotado de la última tecnología» ${ }^{28}$. Y es que uno de los elementos sobre los que ha pivotado la promoción de la sala Phenomena ha sido la superioridad tecnológica de sus instalaciones y de su equipo de proyección, que le ha permitido convertirse en la primera y única sala en España capaz de proyectar en Ultra Panavision, más conocido por ser el formato en el que se rodó el épico Ben-Hur (William Wyler, 1959) y recuperado recientemente por Quentin Tarantino en el wéstern Los odiosos ocho (The Hateful Eight, 2015). En 2015, la sala se jactaba de ser la única pantalla en España en proyectar Los odiosos ocho «siguiendo las indicaciones del propio Tarantino, en versión Roadshow,
[27] Blanca Cia, «Recuperar la ilusión de pisar un cine» (El País Cataluña, 1 de diciembre de 2015). Disponible en: <https://elpais.com/ ccaa/2015/11/30/catalunya/1448914453_240187.html> (10/10/2017).

[28] «La sala» (Phenomena Experience), <http://www. phenomena-experience.com/ sala.html> (8/10/2017).

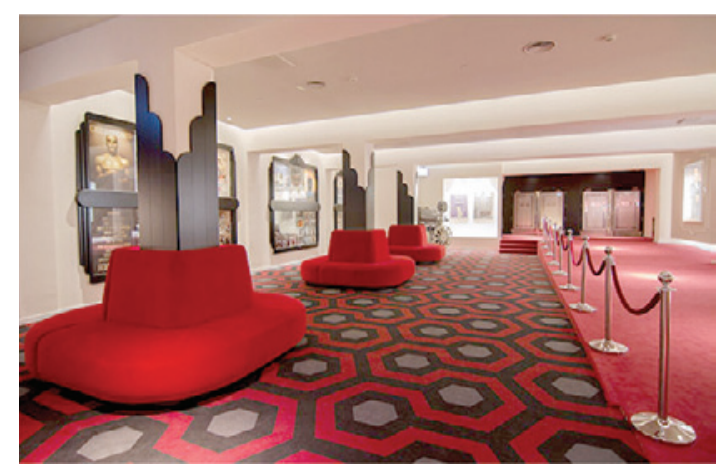

Lounge de la Sala Phenomena Experience, homenaje al hotel Overlook en El resplandor (The Shining, Stanley Kubrick 1980). 
[29] «Noticias», (Phenomena Experience), <http:// www.phenomena-experience. com/noticias/20/.html > $(8 / 10 / 2017)$.

[3o] En internet se recogen algunas crónicas de fans que asistieron al evento. Véase por ejemplo la narración del peregrinaje en Cinemanía. Daniel de Partearroyo, «Por qué me gasté setenta euros en ver $L o s$ odiosos ocho", (Cinemanía, 19 de enero de 2016). Disponible en: <http://cinemania. elmundo.es/noticias/por-queme-gaste-70-euros-en-verlos-odiosos-ocho-en-70mm/> (8/10/2017).

[31] Janet Harbord, «Film Festivals-Time-Event», en Dina Iordanova y Ragan Rhyne (eds.), Film Festivals Yearbook 1: The Festival Circuit (St Andrews, St Andrews Film Studies, 2009), p. 8.

[32] "Akira», (Sunset Cinema), <http://sunsetcinema.es/ film/akira/> (9/10/20017). con varios minutos adicionales y en $70 \mathrm{~mm}{ }^{29}$. La película extendida, que duraba tres horas y dos minutos y que incluía un intermedio de doce minutos, se proyectó en un solo pase a las nueve de la noche el 24 de julio 2016. Esta sesión pretendía emular un Roadshow, pases especiales en gran formato que se hicieron populares en los Estados Unidos entre los años cincuenta y setenta y en los que se proyectaban filmes épicos de larga duración (entre dos y cuatro horas) en varios actos, con intermisiones de entre cinco y quince minutos. De este modo, mientras que por esas mismas fechas diferentes cines del país programaban en sesión continua la versión comercial del filme, Phenomena cargaba la proyección de la ansiedad propia de la oportunidad, anunciándola como una ocasión única, asequible solo a unos pocos afortunados que tuvieron que reservar su butaca con antelación y pagar doce euros por su entrada. Una oportunidad que hizo, incluso, que algunos peregrinaran a Barcelona, solo para asistir al evento ${ }^{30}$.

De la misma manera que los festivales cinematográficos incorporan la urgencia de la ocasión al visionado de la película ${ }^{31}$, el cine-evento manufactura experiencias cinematográficas memorables en un momento histórico en el que ir al cine ha dejado de ser un evento en sí mismo. Las condiciones especiales que acompañaron a la proyección de Los odiosos ocho son un buen ejemplo de cómo el cine-evento trata de extraer la sesión cinematográfica de la cotidianeidad en la que está instalada, ya sea tratando el producto de manera especial o ubicando la proyección cinematográfica en un espacio-tiempo que se haya en discontinuidad con la temporalidad a la que la asistencia al cine nos tiene acostumbrados. Sunset Cinema, consciente de la revalorización que otorga ubicar una proyección en un tiempo singular, anunciaba en su página web la proyección de Akira (Katsuhiro Otomo, 1988) de la siguiente manera:

Sunset Cinema Gold celebra una noche única dedicada a todos los que alguna vez soñaron con disfrutar de $A K I R A$ a lo grande y como se celebran las mayores obras del séptimo arte. Precisamente, cuando a principios de octubre se estrena la esperada Blade Runner 2049, homenajeamos a una de las obras de culto del cine distópico: volvemos a esa megalópolis en una sesión única y diferente que, probablemente, no vuelva a repetirse en muchos años con la obra maestra del ciberpunk ${ }^{32}$.

En esta presentación dramática de la proyección de Akira, Sunset Cinema conecta lo irrepetible del pase con referencias cinéfilas que, se entiende, serán comprensibles para un público especializado y conocedor del subgénero al que homenajea el filme Akira. Encontramos aquí que la convulsión que esta proyección provoca en la vida cotidiana del espectador sirve también para diferenciarlo del resto de espectadores e identificarlo como un espectador aficionado y merecedor de este tipo de proyección exclusiva. En este sentido, si el contexto de exhibición (los Cines Capitol y las sesiones exclusivas de Sunset Cinema Gold) expresa simbólicamente nuestra vinculación a unas culturas del cine determinadas, esta vinculación parece amplificarse con el evento. En su estudio 
en torno al estatus de las actuaciones en directo en la sociedad de masas, Philip Auslander explica la relevancia que el directo y la experiencia de primera mano tienen para el asistente a la hora de conseguir una reputación dentro de un grupo cultural dado:

La dimensión de la cuestión de por qué la gente continúa asistiendo a eventos en vivo en nuestra cultura mediatizada es que los eventos en directo poseen valor cultural: poder decir que se estuvo físicamente presente en un evento concreto constituye un capital simbólico de gran valor... Un aspecto notorio de la posición de la performance dentro de la economía cultural es que nuestra capacidad de convertir la asistencia a un evento en directo en capital simbólico es completamente independiente de la calidad de la experiencia que obtenemos del propio evento ${ }^{33}$.

La temporalidad concreta y puntual que ofrece participar en vivo y en directo en un pase único, unas jornadas de cómic, un festival de cine o en un concierto revaloriza culturalmente la práctica de los asistentes que, por conseguir acceso de primera mano a determinadas personalidades y experiencias, son percibidos por los demás aficionados como más experimentados, más expertos y, en definitiva, mejores «fans». Este estatus de autenticidad que, a ojo de la comunidad de fans, proporciona la cercanía espacio-temporal al objeto de devoción explica, de acuerdo con Matt Hills, la importancia que los festivales de cine de género tienen en el imaginario de los aficionados al cine de terror (a quienes define como fleshand-blood audiences). Los festivales contribuyen a estimular las subculturas del cine de terror creando espacios de encuentro en los que sus aficionados comparten su amor por el género y acumulan capital subcultural ${ }^{34}$. Habría que añadir que el capital simbólico que Auslander le atribuye a la experiencia de participar en un evento (él estudia la subcultura de la música rock y sus derivaciones) no solo confirmaría la posición privilegiada dentro de la estructura social, sino que contribuye a legitimar esta misma estructura social. Veremos a continuación que, en la mayoría de los casos, el cine-evento replantea la relación entre el cine y el público en base a dos distinciones que, siguiendo los términos planteados por Pierre Bourdieu, le permitirían acumular al público capital simbólico: por un lado, una sensibilidad espectatorial que podríamos llamar «purista» y que se expresa en una preferencia anacrónica por el celuloide; y, por otro, la mitificación de la gran pantalla como reducto de una añorada experiencia comunitaria ${ }^{35}$.

\section{Bigger that life o el culto a la gran pantalla}

Si el éxito de la fórmula «Phenomena» se sostiene sobre la expectación que la empresa crea en torno a los pases especiales, lo que verdaderamente permite vivir al espectador la sesión de cine como una oportunidad limitada es la sofisticación del contexto de visionado: la amplitud del patio de butacas, los asientos ergonómicos, la moqueta roja, el telón, el sistema de sonido multidimensional Dolby Atmos y la pantalla panorámica de quince metros de largo forman
[33] Philip Auslander, Liveness: Performance in a Mediatized Culture (London and New York, Routledge, 1999), pp. 5859. (La traducción es nuestra).

[34] Matt Hills, «Attending Horror Film Festivals and Conventions: Liveness, Subcultural Capital and "flesh-and-blood" Genre Communities», en Ian Conrich (ed.), Horror Zone: The Cultural Experience of Contemporary Horror Cinema (London; New York, Tauris, 2010), pp. 90-1.

[35] Que un gran número de autores haya optado por elaborar la cinefilia como una categoría social que descansa sobre discursos de clase, ha terminado por atar la cuestión de la cinefilia a los debates surgidos sobre la baja/alta cultura en los que el concepto de distinción de Pierre Bourdieu (1979) ha desempeñado un papel crucial. Véase Pierre Bordieu, La distinción. Criterio y bases sociales del gusto (Madrid, Taurus, 1998). 
[36] «Inauguración de la Sala Phenomena, hablamos con Nacho Cerdà» (El Séptimo Arte, 24 de diciembre, 2014). Disponible en: <http://www. elseptimoarte.net/noticias/ entrevistas/inauguracion-dela-sala-phenomena-hablamoscon-nacho-cerda-22623.html> (3/10/2017).

[37] «Cines Capitol» (Sunset Cinema), <http://sunsetcinema.es/cine-capitol/> (3/10/2017). parte de lo que podríamos definir como una fetichización de esa experiencia «tradicional» de ir al cine que Phenomena desea dramatizar. Poco después de inaugurar la sala, Cerdà explicaba en una entrevista para el webzine El Séptimo Arte el origen del proyecto y las razones que le habían motivado a abrir una sala de estas características.

Es la reinterpretación de algo que ya existía. Es la resurrección de lo que en su momento se denominó como «el cine de barrio». Quería recuperar dos cosas: las películas que forman parte de nuestra cultura cinematográfica y cinéfila y hacer todo esto en un entorno más adecuado y más parecido al de la sala de cine «de antes». Quería dar un punto de espectacularidad al ritual social, al encuentro con otros espectadores... a toda esa actividad que se montaba alrededor de una sala de cine y que ahora, desgraciadamente, creo que se ha ido perdiendo ${ }^{36}$.

Si atendemos a las palabras de Cerdà, lo que diferenciaría a Phenomena del resto de salas es que pone en escena una experiencia cinematográfica que, de acuerdo con el cineasta, ha dejado de existir en el espacio público. En Phenomena, tanto la programación como la puesta en escena retrospectiva invitan a una suerte de viaje en el que la nostalgia activa formas de recepción colectiva más comunitarias y que, según Cerdà, se corresponderían con «toda esa actividad que se montaba alrededor de una sala de cine». Proporcionando a las películas «un entorno más adecuado» o más cercano a la sala de cine «de antes», las sesiones de Phenomena cargan el visionado colectivo de ritualidad en un sentido mágico-antropológico: vigorizan esos vínculos sociales que, desde el punto de vista de estos organizadores, amenazan con disolverse. Si miramos hacia el panorama del cine-evento en España, descubrimos que esta expresión de nostalgia por la experiencia cinematográfica perdida reaparece de forma constante. En su página web, Sunset Cinema invita a los espectadores a asistir a sus proyecciones en los Cines Capitol en los siguientes términos:

Revive, o descubre por primera vez, ese magnetismo energético y único que se siente en una sala con más de mil espectadores disfrutando, todos al mismo tiempo, de los diálogos, silencios, miradas y, en definitiva, de la verdadera magia del cine más absoluto (...). Ir al cine era todo un acontecimiento social, una experiencia común y compartida, lejos del individualismo con el que operamos hoy en día ${ }^{37}$.

En este caso, la sala uno de los Cines Capitol, donde Sunset Cinema celebra desde 2017 sus sesiones especiales Sunset Cinema Gold, se convierte en un espacio conmemorativo en el que celebrar la experiencia «auténtica» del cine. Este multicine, uno de los más emblemáticos de la capital y activo desde el año 1933, funcionaría como una suerte de objeto de culto cuya historia conecta a los espectadores con la perfección original de la proyección: ese momento de descubrimiento de la imagen como momento de revelación cinéfila por excelencia. Ahora bien, resulta llamativo que, en el discurso de Sunset Cinema, lo que se enfatiza no es la experiencia inmersiva (potenciada, se entiende, por las 
cualidades tecnológicas de la sala), sino lo excepcional de participar en una experiencia comunitaria. La sala aparece aquí como garantía de un acontecimiento social único en el que es posible sentir el «magnetismo» de los otros. Esta presentación de la sala de cine como espacio en el que se satisface una determinada demanda por vivir experiencias vicarias y afectivas conecta con algunas consideraciones que han estudiado la asistencia al cine como una actividad fundamentalmente social ${ }^{38}$. Así, por ejemplo, frente a los estudios que han dado por sentado que asistir al cine es una experiencia silenciosa e introspectiva, Garth Jowett y James M. Linton describen el acto de estar dentro de una sala como una experiencia esencialmente colectiva en la medida en la que «el mensaje no solo va de la pantalla al individuo, sino que este mensaje es reinterpretado, realzado, amplificado, disminuido o incluso malinterpretado por la interacción con otros miembros de la audiencia» ${ }^{39}$. Esta relación que tanto Sunset Cinema como Phenomena establecen entre el celuloide y la sala, como antídotos al exceso de individualismo que sufre nuestra sociedad, reaparece en la siguiente reflexión de Rubén Lardín, cocreador de las sesiones itinerantes de cine de serie $\mathrm{B}$ y de culto Trash entre amigos:

\begin{abstract}
Yo creo que estas sesiones-evento funcionan ahora mejor que nunca, porque la gente quiere recuperar la sensación de comunión de ir al cine. Estar ahí en una sala llena de gente. Lo que me interesa de las películas que ves con gente en una sala es que se fijan en la memoria ${ }^{40}$.
\end{abstract}

De acuerdo con Lardín, «ver una película en una sala llena de gente» contribuye a asentar experiencias memorables frente a otras formas de ver cine, se entiende, solitarias, que no dejarían un residuo. Desde este punto de vista, el cine evento vendría a solucionar una deficiencia antropológica que, supuestamente, afecta a nuestras prácticas de visionado y a nuestra relación misma con el cine en la actualidad. Enfatizando la importancia que la memoria tiene en la experiencia fílmica, Lardín construye el discurso del cine-evento como contrapartida a internet y a las formas de visionado que él y los demás organizadores de este tipo de sesiones consideran «perecederas». Esta oposición esencial entre «la gran pantalla» e internet, como medio que priva al espectador de la dimensión social del cine, se expresa de manera explícita en una columna que la cineasta Isabel Coixet dedicaba a la sala Phenomena en El Periódico:

Ver cualquier película en este cine es volver a sentir esa sensación de 'Bigger than life' (Más grande que la vida) del cine de verdad: el cine que no se ve a trompicones en móviles, iPads, aviones. El cine en el que uno presta atención a la pantalla y a la película, sin que haya irrupciones de la vida cotidiana, llamadas, ruidos, wasaps, consultas a Facebook ${ }^{41}$.

Como demuestran estas declaraciones, la percepción de que la cibercultura está suplantando nuestra experiencia real y locativa de la esfera pública es una preocupación que todavía permanece latente cuando toca hablar de la experiencia social de ir a cine. Aquí, internet y, en particular, las redes sociales
[38] Véase Graeme Turner, Film as Social Practice (London, New York, Routledge, 1999); Garth Jowett y James M. Linton, Movies as Mass Communication (London, Sage, 1989).

[39] Garth A. Jowett y James M. Linton, Movies as Mass Communication, p. 103. (La traducción es nuestra).

[4o] Rubén Lardín, (entrevista personal, 3 de noviembre de 2016).

[41] Isabel Coixet, «Phenomena» (El Periódico, 3 de junio de 2015). Disponible en: <http:// www.elperiodico.com/es/opinion/20150603/phenomenapor-isabel-coixet-4244374> (4/10/2017). 
[42] Thomas Elsaesser, «Cinephilia or the Uses of Disenchantment», en Marijke de Valck y Malte Hagener (eds.), Cinephilia. Movies, Love and Memory (Amsterdam, Amsterdam University Press, 2005), pp.27-8. (La traducción es nuestra).

[43] Barbara Klinger, Beyond the Multiplex: Cinema, New Technologies, and the Home (California, University of California Press, 2006).

[44] Barbara Klinger, Beyond the Multiplex: Cinema, New Technologies, and the Home, p.4. (La traducción es nuestra).

[45] Richard McCulloch y Virginia Crisp, "Watch like a grown up ... enjoy like a child': Exhibition, Authenticity, and Film Audiences at the Prince Charles Cinema», p. 208. se conciben como una esfera importante de la vida del espectador que, sin embrago, le priva del acontecimiento social que en este caso significa estar en una sala viendo una película en el formato «apropiado». Frente a la imperfección de los dispositivos móviles y la inautenticidad de las redes sociales, el celuloide aparece aquí como la quintaesencia de una experiencia anacrónica pero añorada precisamente por ser auténtica: un espacio de la vida cotidiana que, en plena vorágine mediática, no defrauda. La polarización que Coixet hace entre los nuevos medios y el celuloide descuida en parte una visión integral del cine como proceso cultural en el que las redes sociales y otras formas de comunicación social online son espacios en los que un sector importante del público está dando coherencia a su actividad cinéfila. De ahí que este punto de vista no deje de formar parte de la clásica melancolía del cinéfilo que, como muy bien expresa Thomas Elsaesser, se encuentra «siempre preparado para rendirse ante la ansiedad de la posible pérdida, para llorar la una vez sensual-sensorial plenitud de la imagen de celuloide y para insistir en la irrecuperable y fugaz naturaleza de la experiencia fílmica» ${ }^{42}$.

Esta discusión en torno a la mitificación de la «gran pantalla» como experiencia connotada de un elemento social, que las nuevas prácticas de consumo de audiovisual están amenazando, remite de manera clara a la contraposición entre el cine y home cinema, un conflicto que Barbara Klinger describe en extensión en Beyond the Multiplex ${ }^{43}$. Klinger sostiene que, desde la aparición de la televisión, toda una serie de tecnologías que enriquecen la calidad del visionado y su experiencia inmersiva en el hogar (como el vídeo, el DVD, el disco láser, el home cinema o el Blue-Ray) han tendido a ser identificadas con formas inauténticas y menos cinéfilas de visionado, mientras que la sala y el celuloide han sido identificados como una extensión lógica del cinéfilo cuyo amor por el cine solo es demostrable a través de su presencia en el espacio solemne de la sala. Para Klinger, esta dicotomía representa la esquizofrenia en la que se encuentra atrapado el debate en torno a la recepción cinematográfica:

[el cine] existe, por un lado, como un medio para salas proyectado en celuloide y, por otro, como un medio presentado, en este caso, en formato de vídeo o para televisión. El evento de la gran pantalla se define como auténtico y como la representación del cine genuino. En contraste, el video se caracteriza no solo como inauténtico y sucedáneo, sino como un lamentable triunfo de la conveniencia sobre el arte que trastorna la comunión entre el espectador y la película e interfiere en los juicios de calidad ${ }^{44}$.

Klinger continúa argumentando que, a pesar de la posición secundaria que el vídeo y las nuevas tecnologías han ocupado en la presentación de la cinefilia en la sociedad, lo cierto es que estas tecnologías son tan importantes en la construcción del imaginario cinéfilo como lo son para la distribución. Ahora bien, como han demostrado McCulloch y Crisp, todo parece indicar que la condición ritual de ver cine en una sala con los demás sigue estando en la cima del imaginario de los amantes del $\operatorname{cine}^{45}$; un sentimiento del que, como hemos 
podido observar hasta hora, el cine-evento se ha apropiado. Finalmente, conviene prestar atención a aquellos elementos que, en el discurso de los organizadores, construyen al público del cine-evento como un público sensible a lo especial y privilegiado, que merece un espacio distinguido respecto al común de los espectadores.

\section{Las fiestas del cine: Bang Bang Zinema}

Si Sunset Cinema y Phenomena representan la versión más profusa del cineevento en España, podemos citar toda una serie de eventos que han emergido y que, partiendo de una programación similar, reivindican formas de visionado más desenfadadas. La más veterana, Trash entre amigos, es una co-creación del cineasta Nacho Vigalondo y los críticos Rubén Lardín, Rubén Minchinela y David Ausente. Estos cuatro amigos, vinculados al mundo del fanzine y a la afición al cine fantástico y de terror, proponen proyecciones itinerantes de cine de serie B y Z, que ellos mismos comentan en clave de humor con micrófonos, emulando una sesión de quote-a-long. Trash entre amigos pretende homenajear la fórmula de las Midnight Movies, sesiones de cine de calidad «dudosa» que se popularizan en los setenta en los Estados Unidos y que, posteriormente, recuperan en los años ochenta festivales de cine de terror y fantástico, como el Festival Internacional de Cine Fantástico de Bruselas, cuyos programadores, como explica Van Extergem, «no tienen miedo de programar algunas de las peores películas, particularmente a media noche, para el deleite de una audiencia embravecida e irreverente» ${ }^{4}$.

En esta misma línea irreverente, en San Sebastián, se celebra desde 2014 Bang Bang Zinema, sesiones que explotan el éxito del reestreno de «clásicos» de los setenta, ochenta y noventa en gran formato. Esta cita se ha convertido en una suerte de secuela (y de precuela) de la veterana Semana de Cine Fantástico y de Terror de San Sebastián/Donostia, que se celebra en la ciudad costera a finales de octubre desde 1990. Estas sesiones no solo comparten público y espacio con el festival (el Teatro Principal, en el casco antiguo de la ciudad), sino que presentan el mismo espíritu participativo y "gamberro» provocado por la propia audiencia que ameniza las sesiones con comentarios, gritos y bromas que se mueven entre la espontaneidad y la farsa guioniza$\mathrm{da}^{47}$. Si en su caracterización como evento de culto, Trash entre amigos presenta una fórmula más minoritaria y más abiertamente opuesta a la cultura
[46] Dirk Van Extergem, «A Report on the Brussels International Festival of Fantastic Film», en Ernest Mathijs y Xavier Mendik (eds.), Alternative Europe: Eurotrash and Exploitation Cinema Since 1945, (Londres, Wallflower Press, 2004), p.217. (La traducción es nuestra).

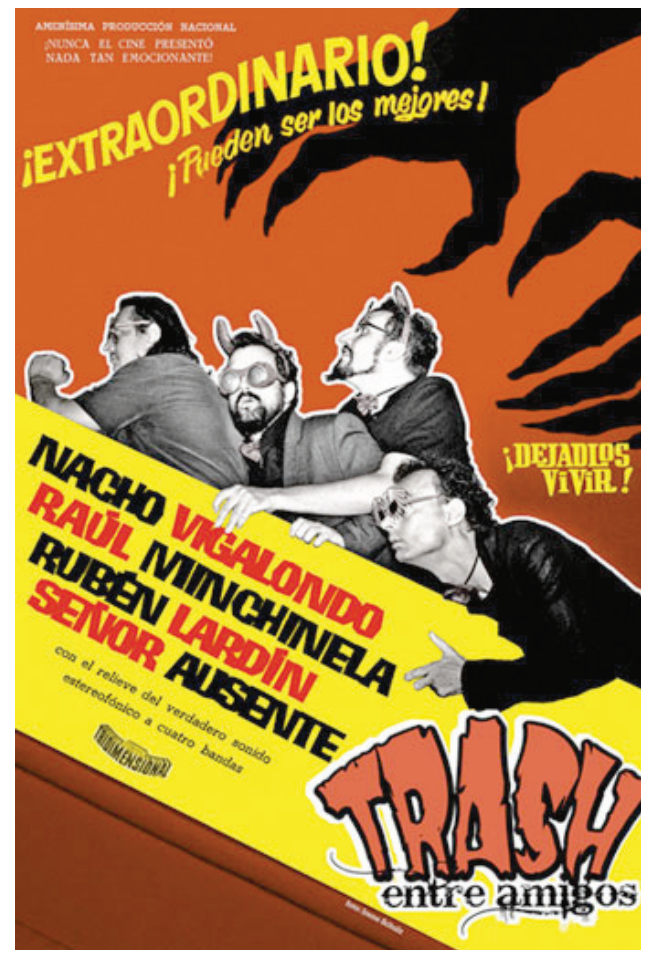

Cartel de las sesiones Trash entre amigos, con sus creadores. 


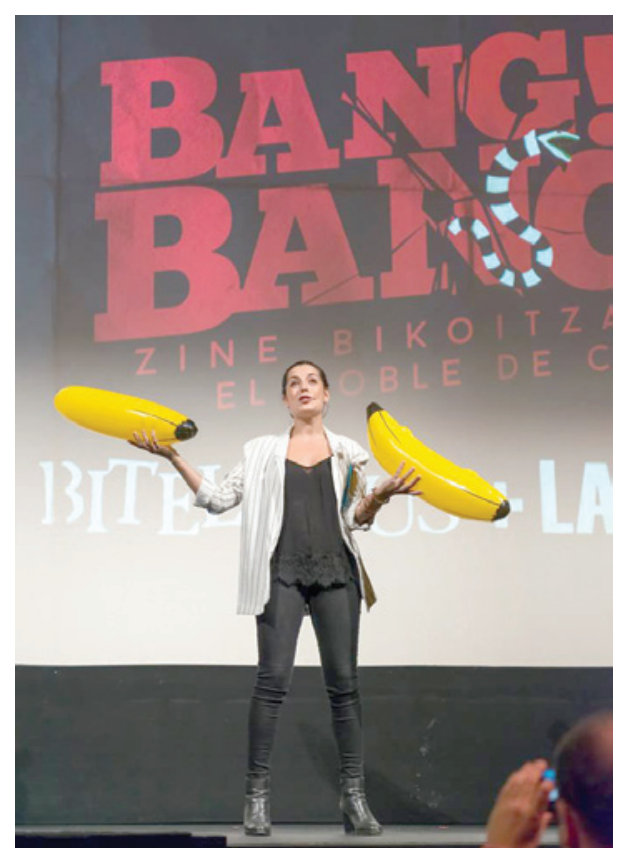

Presentación Bang Bang Zinema de la sesión doble Bitelchús (Beetlejuice, Tim Burton 1988) + La cosa (The Thing, John Carpenter 1982) el 21 de octubre de 2017, en el Teatro Principal de Donostia/San Sebastián.

masiva, Bang Bang Zinema lanza un mensaje inclusivo, muy próximo a la «factoría» Phenomena. En una entrevista personal, Alfonso López, cocreador de las sesiones Bang Bang Zinema, narra de la siguiente forma el origen del proyecto:

Con Bang Bang queremos recuperar el espíritu de las sesiones de cine dobles de nuestra infancia, de ese cine festivo y sin ninguna pretensión más que disfrutar de la experiencia de ir al cine con más gente y pasar un buen rato con tus ami$\operatorname{gos}^{48}$.

La nostalgia por la experiencia cinematográfica perdida emerge aquí de manera más evidente en la mención de la infancia y las sesiones dobles, que invocan un tiempo menos corrompido por la tecnología y que puede ser recuperado o reconstruido para las audiencias del presente. No es solo que el propio hecho de asistir a una sala se presente como una práctica más auténtica en la medida que se encuentra más próxima a un momento original imaginario (un momento en el que las tecnologías de la comunicación y la imagen no formaban parte de nuestra relación cotidiana con el cine), sino que el propio repertorio de películas que estos eventos proyectan -Los Gremlins (Gremlins, Joe Dante, 1984), Alien (Ridley Scott, 1979), Willow

[47] Rosana Vivar, «Never Seen a Shot Like That Before! Playfulness and Participatory Audiences in San Sebastian Horror and Fantasy Film Festival», en Sarah Atkinson y Helen Kennedy (eds.), Live Cinema: Cultures, Economics, Aesthetics (Londres, Bloomsbury, 2017).

[48] Alfonso López, (entrevista personal, 2 de noviembre, 2015).

[49] Richard McCulloch y Virginia Crisp, "Watch like a grown up... enjoy like a child': Exhibition, Authenticity, and Film Audiences at the Prince Charles Cinema».

[5o] Lluís Duch, Antropología de la vida cotidiana. Simbolismo y salud (Madrid, Trotta, 2002), p. 196.
(Ron Howard, 1988) - invoca toda una serie de emociones compartidas por el público que remiten al pasado personal y a las primeras experiencias de visionado de una generación que, hoy, se encuentra en la franja de edad ente los treinta y los cincuenta años. En este sentido, no es baladí que Alfonso López mencione el placer que en estas sesiones provoca la posibilidad de compartir una sesión de cine familiar con amigos que, potencialmente, ya habrán visto la película. Si añadimos que en Bang Bang Zinema, la experiencia cinematográfica viene amplificada por la posibilidad de hacer comentarios y disfrutar de una atmósfera relajada más propia del salón de una casa que de un cine, estas sesiones conectarían más con la cultura del DVD y el home-cinema que con la melancolía cinéfila asociada a la gran pantalla ${ }^{49}$.

Esta suerte de restablecimiento de la unidad perdida que los organizadores de estos eventos invocan cuando hablan de recuperar la perfección original del cine (ya sea emulando la emoción ante la gran pantalla o las memorias de las películas en VHS) conecta al cine-evento con la ideología propia de los rituales y las fiestas periódicas que, de acuerdo con el antropólogo Lluis Duch, imponían «la necesidad de retornar ritualmente a los orígenes, aquella situación anterior al tiempo en la que todo era puro e incontaminado» ${ }^{\circ}$. Si acudimos a una definición antropológica de la fiesta, Roger D. Abrahams sostiene en este 
sentido que «tanto las ferias como las fiestas operan en la zona de la nostalgia, ya que son recordatorios de una vida en una economía y una tecnología más simples, cuando los individuos se valían por sí mismos» ${ }^{51}$. Esta identificación, que en el cine-evento se produce entre el cine y las formas rituales de rememoración cultural, justificaría buena parte de la ceremonia que se reproduce en estas sesiones. Pero, ante todo, el ceremonial que el público dramatiza en los eventos citados dibujaría al público como «poseedor de un secreto» (pensemos en las sesiones de Secret Cinema) que solo los miembros de la audiencia conocen y que usan para demarcarse de otras audiencias.

Podemos argumentar, por tanto, que esta caracterización festiva de la sesión de cine que promueve el cine-evento va encaminada a dramatizar un sentido de exclusividad entre los miembros del público, una exclusividad que nace de una relación especial entre los espectadores y el tipo de películas que se proyectan. Esta diferencia esencial entre espectadores que el evento pretende enfatizar viene establecida ya por el conjunto de títulos que configuran el programa habitual de estas sesiones-experiencia. Bitelchús (Beatlejuice, Tim Burton, 1988), Aterriza como puedas (Airplane! David Zucker, Jerry Zucker y Jim Abrahams, 1980), Amor a quemarropa (True Romance, Tony Scott, 1993), Atrapado en el tiempo (Groundhog Day, Harond Ramis, 1993), Pulp Fiction (Quentin Tarantino, 1994), Dirty Dancing o El club de la lucha (The Fight Club, David Fincher,1999) conjugan una lista de filmes que mezcla sin complejos títulos «cinéfilos» con otros más comerciales y próximos al cine mainstream que se distancian de lo que, desde una perspectiva canónica, podría considerarse «buen» cine. Esta actitud desprejuiciada hacia un gusto cinematográfico en el que cabe todo se confirma en las palabras con las que Nacho Cerdà hace referencia al criterio que define la marca de la casa: «no le hacemos ascos a nada: cualquier película puede formar parte de Phenomena» ${ }^{2}$.

Aunque, atendiendo a las palabras de Cerdà, Phenomena parece definirse por ser un producto abierto y atractivo al total de espectadores, su programa se basa en un rechazo hacia los productos y las formas de recepción canónicas que se consideran «legítimas» y, en especial, hacia la cinefilia, entendida como la forma de consumo erudita preferida entre las élites culturales ${ }^{53}$. La preferencia de estas sesiones por una lista de «clásicos», que quedan fuera del canon cinéfilo, sitúa al público de estos eventos en las antípodas del gusto de las audiencias «normales» ${ }^{54}$ y los acerca a una sensibilidad subcultural que, en España, algunos han descrito como «cinéfaga». En los trabajos de Cristina Pujol (2011) y Jesús Palacios (2006), la «cinefagia» se describe como la forma de consumo «depredadora» de aquellos espectadores que se ubican culturalmente en oposición a la erudición y las formas más «selectas» y aburguesadas de consumo cinéfilo $^{55}$. Es decir, son consumidores ávidos de películas que practican un consumo acrítico, viendo todo lo que se les pone por delante sin aplicar criterios de distinción o calidad. Esta categoría, no obstante, resulta problemática en el momento en el que la contraponemos a una cinefilia que, además de en salas, consume cine en televisión, en plataformas de vídeo a demanda, en cinetecas
[51] Roger D. Abrahams, «An American Vocabulary of Celebrations», en Alessandro Falassi (ed.), Time Out of Time: Essays On the Festival, (Albuquerque, University of New Mexico Press, 1987), p. 181. (La traducción es nuestra).

[52] David Morán, «Phenomena. El cine como experiencia y ritual» $(A B C, 19$ de diciembre de 2014). Disponible en: <http://www.abc.es/catalunya/barcelona/20141219/abciphenomena-cine-como-experiencia-201412191039.html> (8/10/2017).

[53] Cristina Pujol, Fans, cinéfilos y cinéfagos: Una aproximación a las culturas y los gustos cinematográficos (Barcelona, Editorial UOC, 2011), p.118.

[54] John Fiske, «The Cultural Economy of Fandom», en Ernest Mathijs y Xavier Mendik (eds.), The Cult Film Reader (Maidenhead, Open University Press, 2007), p. 446.

[55] Cristina Pujol, Fans, cinéfilos y cinéfagos; Jesús Palacios, ¿Qué debes saber para parecer un cinéfilo? (Madrid, Espasa, 2006). 
en línea, sin olvidar el DVD y los formatos de nueva generación como el disco Blue-Ray. No en vano, la accesibilidad que estas plataformas ofrecen nos permite pensar hoy en día en el/la cinéfilo/a como «devorador/a de películas». La erudición cinéfila, por tanto, contrastaría con esa forma de consumo depredadora de la que se jactan hoy muchos cinéfilos y por la que se «engulle» sin pausa todo el cine disponible.

En último término, estas categorías no dejarían de enfatizar la posición ambivalente que estas sesiones evento ocupan en el marco de la cultura cinematográfica actual. En su énfasis por introducir formas ideales y necesarias de ver cine en el panorama de exhibición actual, estas sesiones combinan discursos asociados al mito de la gran pantalla, con la comodidad y la familiaridad de las sesiones de cine en casa. Es decir, en estas sesiones la reverencia al celuloide, al gran formato como forma «apropiada» de ver cine es compatible con las formas más irreverentes de visionado, con el comentario y con la cultura del home-cinema.

\section{Conclusión}

Si el cine ha poseído siempre las cualidades propias del acontecimiento, las experiencias descritas más arriba demuestran que el evento define cada vez más el trasfondo de nuestra existencia como espectadores. La experiencia del público está hoy marcada por la estacionalidad y por la ocasión más que por las películas que vemos. Esto no solo se percibe en el tipo de proyecciones participativas y catárticas examinadas arriba, sino, ante todo, en las nuevas formas de recepción ocasional que se organizan en salas privadas y centros culturales que, como Cineteca (Madrid), Tabakalera (San Sebastián), La Caixa Forum (Madrid y Barcelona) y Filmotecas, se han convertido en espacios anfitriones de festivales, ciclos y pases únicos. El evento connota al visionado de elementos que lo hacen único y especial, pero también connota a los espectadores como miembros de la audiencia que han escogido estar ahí en lugar de asistir a una película «en cartel».

Si bien el cine-evento se ha convertido en una práctica normalizada dentro de la exhibición cinematográfica nacional, podemos concluir que este fenómeno se está construyendo sobre una retórica de anhelo cultural por una dimensión social del cine que, de acuerdo con buena parte de sus promotores, nos está siendo arrebatada por los nuevos modelos de consumo que se gestan en torno a los servicios de distribución de cine a demanda. En este sentido, las declaraciones de los organizadores aquí examinadas demuestran que el énfasis en torno a la necesidad de estas proyecciones-experiencia se sostiene sobre la idea postiza de que buena parte de los consumidores de cine ansían experiencias vicarias que mitiguen la sensación de pérdida generada por la dispersión de los espectadores en el ciberespacio. Como hemos podido comprobar, este discurso no solo se nutre de un feroz anacronismo, sino que descubre toda una serie de dogmas acerca del espectador actual que remite a la artificial división del público entre espectadores activos/competentes (aquéllos capaces de reconocer experiencias cinematográficas vicarias en las que reside la especificidad 
del cine) y espectadores pasivos/complacientes (los que se conforman con formas más «convencionales» de visionado).

Presentando el cine-evento como un espectáculo cinematográfico que nace en oposición a formas no-comunitarias de ver cine (y sus tecnologías asociadas), sus promotores vinculan estas proyecciones a gustos e identidades subculturales que buscan espacios de exclusividad (y de exclusión) dentro de una industria que se sabe comercial y que busca establecerse como marca dentro de la programación cultural de ciudades como Barcelona y Madrid. Con todo, no deja de ser llamativo que la manera en la que estas sesiones se desvinculan de los modos de ser del «cine vigente» (su estética, su moral, sus protocolos de visionado) sea a través de títulos cuyo público ha descubierto en el contexto doméstico de la programación televisiva, el VHS y el DVD. Es esto lo que nos lleva a vincular el fenómeno del cine-evento en España con una cierta nostalgia generacional que reverencia y ritualiza la mirada fascinada hacia la cultura popular de los ochenta y los noventa.

En último término, consideramos que el llamado cine-evento, al igual que los festivales cinematográficos y otras fórmulas que eventualizan la experiencia fílmica en el espacio urbano, ejemplifican una tendencia cultural que se basa en crear relaciones de exclusividad entre el cine y el público como condición de acceso a ciertos productos fílmicos. En otras palabras, nos encontramos ante un fenómeno que, en su forma de concebir espacios nicho y de distinción cultural en la esfera pública, se ubica en ese espacio fronterizo que une y, a la vez, distingue el culto y la cultura (una forma de presentar el consumo y la producción cultural en la que se ha especializado la cultura masiva).

Abriendo una veda a investigaciones futuras, sería de gran interés llevar a cabo un estudio etnográfico del público de este tipo de sesiones con el fin de tener una mayor comprensión del atractivo que estas sesiones tienen para sus asistentes. Creemos que esta investigación debe empezar por una mejor conceptualización del cine de culto y de las devociones rutinarias que este tipo de cine suscita en nuestra sociedad. Como reflexión final, consideramos que el éxito que estos eventos están teniendo en España pone en evidencia la necesidad de empezar a prestar más atención a los espacios en los que se consumen películas de forma colectiva en un momento en el que el cine ha dejado de ser una actividad exclusiva del espectador y empieza a ser dominio del usuario.

\section{FUENTES PRIMARIAS}

LARDín, Rubén, «entrevista realizada por la autora» (3 de noviembre de 2016).

López, Alfonso «entrevista realizada por la autora» (2 de noviembre de 2015).

\section{BIBLIOGRAFÍA}

Aвrahams, Roger D. «An American Vocabulary of Celebrations», en Alessandro Falassi (ed.), Time Out of Time: Essays on the Festival (Albuquerque, University of New Mexico Press, 1987), pp. 173-83 . 
Amorós, Vicente, Luces de candilejas (Madrid, Espasa Calpe, 1991).

Atrinson, Sarah y Kennedy, Helen (eds.), Live Cinema: Cultures, Economics, Aesthetics.

(Londres, Bloomsbury, 2017).

-, «Inside-the-scenes: The Rise of Experiential Cinema» (Participations. Journal of Audience and Reception Studies, vol. 13, n. ${ }^{\circ}$ 1, mayo de 2016), pp. 139-51. Disponible en: <http:// www.participations.org/Volume\%20 13/Issue\%201/S1/1. pdf>

AusLAnder, Philip, Liveness: Performance in a Mediatized Culture (Londres y Nueva York, Routledge, 1999).

BARKer, Martin, Live to Your Local Cinema: The Remarkable Rise of Livecasting. (Basingstoke, Palgrave Macmillan, 2013).

BENET, Vicente J, La cultura del cine (Barcelona, Paidós, 2004).

Bordieu, Pierre, La distinción. Criterio y bases sociales del gusto (Madrid, Taurus, 1998) Duch, Lluís, Antropología de la vida cotidiana. Simbolismo y salud (Madrid, Trotta, 2002).

ELSAESSER, Thomas. «Cinephilia or the Uses of Disenchantment», en Marijke De Valck y Malte Hagener (eds.), Cinephilia. Movies, Love and Memory (Amsterdam, Amsterdam University Press, 2005), pp. 27-44.

Fiske, John, «The Cultural Economy of Fandom», en Ernest Mathijs y Xavier Mendik (eds.), The Cult Film Reader (Maidenhead, Open University Press, 2007).

GANT, Charles, «Sharing the Secret» (Sight \& Sound, 20, n. ${ }^{\circ}$ 9, septiembre de 2010), p. 9. GoNZÁLEZ RUEDA, Ana, «Cibeles como una propuesta distinta de cine de verano» (El Mundo, 9 de julio de 2015). Disponible en: <http://www.elmundo.es/madrid/2015/07/ o8/559d4b60268e3eeo428b4591.html>

HARBORD, Janet, «Film Festivals-Time-Event», en Dina Iordanova y Ragan Rhyne (eds.), Film Festivals Yearbook 1: The Festival Circuit (St Andrews, St Andrews Film Studies, 2009).

Hills, Matt. «Attending Horror Film Festivals and Conventions: Liveness, Subcultural Capital and "flesh-and-blood Genre Communities"», en Ian Conrich (ed.), Horror Zone: The Cultural Experience pf Contemporary Horror Cinema, (Londres; Nueva York, Tauris, 2010), pp. 87-101.

Jowetr, Garth y Linton, James M., Movies as Mass Communication (Londres, Sage, 1989). Kennedy, Helen, «Funfear Attractions: the Playful Affects of Carefully Managed Terror in Immersive 28 days later Live Experiences», en Sarah Atkinson y Helen Kennedy (eds.), Live Cinema: Cultures, Economics, Aesthetics (Londres, Bloomsbury, 2017).

KuInger, Barbara, Beyond the Multiplex: Cinema, New Technologies, and the Home. (University of California Press, 2006).

MCCulloch, Richard y CRISP, Virginia, “'Watch like a grown up ... enjoy like a child’: Exhibition, Authenticity, and Film Audiences at the Prince Charles Cinema» (Participations. Journal of Audience and Reception Studies 13, n. ${ }^{\circ}$ 1, mayo de 2016), pp. 188-217.

PaLACIOS, Jesús, ¿¿Qué debes saber para parecer un cinéfilo? (Madrid, Espasa, 2006).

Pusol, Cristina, Fans, cinéfilos y cinéfagos: Una aproximación a las culturas y los gustos cinematográficos (Barcelona, Editorial UOC, 2011).

Tsivian, Yuri, Early Cinema in Russia and Its Cultural Reception (Londres; Nueva York, Routledge, 1998).

Tuck, Fiona y Aвrahams, Mitra, «Understanding the Impact of Event Cinema: an Evidence Review». (Trends Business Review for Arts Council and BFI, 2015). Disponible en: <https://www.artscouncil.org.uk/sites/default/files/download-file/ Understanding_the_impact_of_event_cinema.pdf> 
Turner, Graeme, Film as Social Practice (Londres; Nueva York, Routledge, 1999).

VAN Extergem, Dirk, «A Report on the Brussels International Festival of Fantastic Film», en Ernest Mathijs y Xavier Mendik (eds.), Alternative Europe: Eurotrash and Exploitation Cinema Since 1945 (Londres, Wallflower Press, 2004), pp. 216-27.

VIVAR, Rosana. «Never Seen a Shot Like That Before! Playfulness and Participatory Audiences in San Sebastian Horror and Fantasy Film Festival », en Sarah Atkinson y Helen Kennedy (eds.), Live Cinema: Cultures, Economics, Aesthetics (Londres, Bloomsbury, 2017).

Recibido: 15 de octubre de 2017

Aceptado para revision por pares: 21 de noviembre de 2017

Aceptado para publicación: 31 de mayo de 2018 


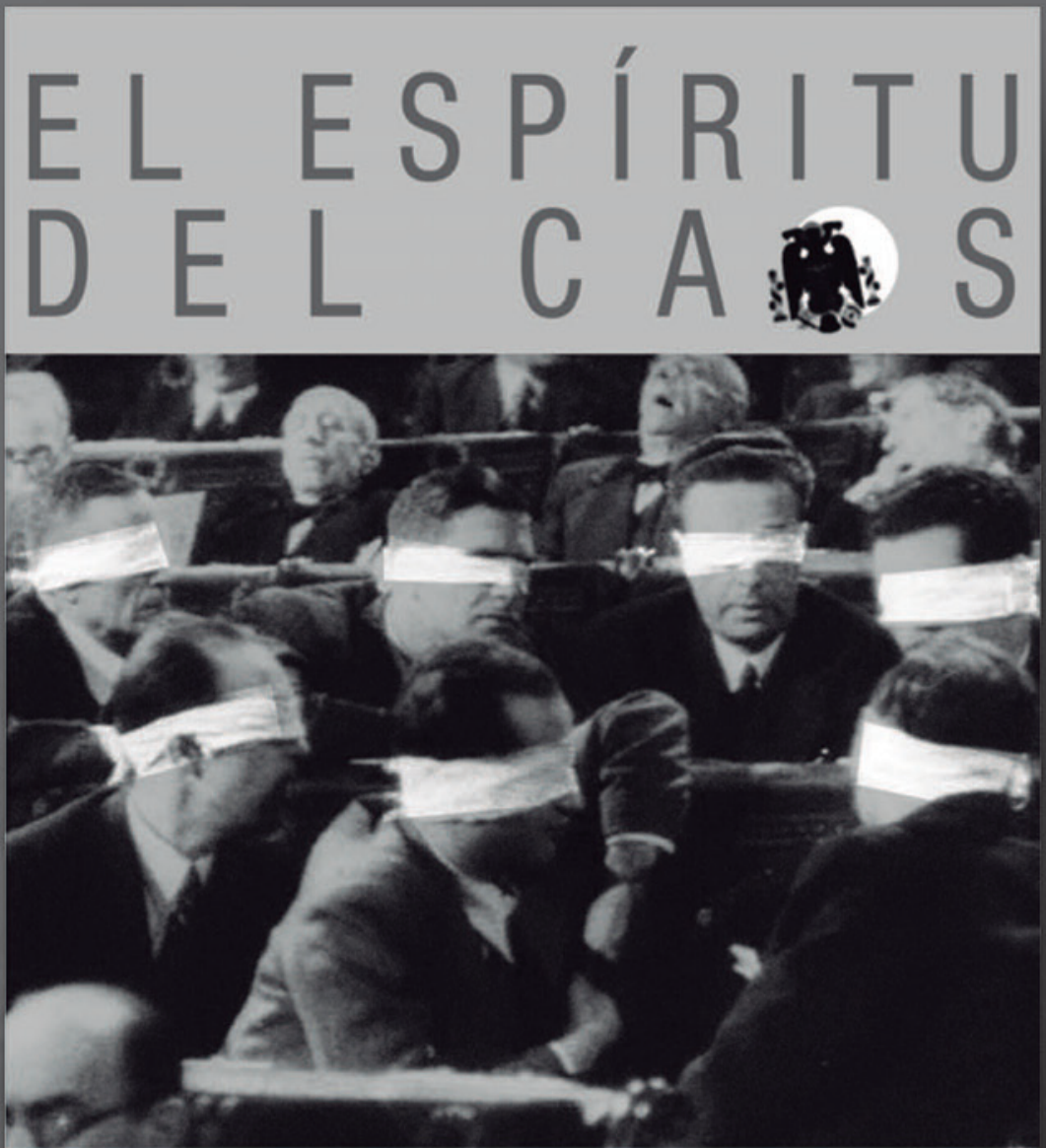

REPRESENTACIÓN Y RECEPCIÓN DE LAS IMÁGENES DURANTE EL FRANQUISMO

(Una recopilación de Secuencias. Revista de Historia del cine) LAURA GÓMEZ VAQUERO Y DANIEL SÁNCHEZ SALAS (EDS.)

Recopilación de artículos aparecidos en Secuencias. Revista de Historia del Cine acerca de una de las etapas del audiovisual más estudiadas en nuestro pais, aquella que coincide con la dictadura franquista.

Los textos incluyen algunos de los descubrimientos más insólitos en el terreno del audiovisual y constituyen una muestra de las perspectivas que se pueden adoptar en la comprensión de los distintos productos cinematográficos y televisivos realizados durante esos años.

592 páginas.

ISBN 978-84-96582-36-1

INFORMACIón Y VENTA: OCHO Y MEDIO, LIBOS DE CINE. Martín de los Heros, 11. 28008 MADRID Tel. 915590628 , tax 9154006 72, libros@ochoymedio com 
